\title{
Innovation Analysis on the Enterprise Marketing Mode in the Background of New Media
}

\author{
$\mathrm{Xu} \mathrm{Zhu}$ \\ Liaoning Jianzhu Vocational College, Liaoning, Liaoyang, 111000, China
}

\begin{abstract}
The rapid development and extensive application of new media technology has brought great impact on the Chinese marketing field, but also brought many opportunities for the marketing transformation and expansion. In order to present the basic situation of China's marketing development in the new media environment, this article focuses on the transformation of the marketing idea in the new media environment, the innovation of the marketing platform and transformation development of industry marketing.

Keywords: innovation analysis, enterprise marketing mode, new media
\end{abstract}

\section{Introduction}

With the rapid development of economy, the market environment of Chinese enterprises has also undergone tremendous changes, and, this change is reflected in all aspects, in which, for marketers, the most profound impact of the two aspects, Consumer changes and changes in the media environment. Regardless of what happens, will force the marketers to change the marketing strategy, follow the needs of market development, in order to gain a place in the market competition. Therefore, the market for our country, we must fundamentally realize that the realization of profit must be to create customer conditions, no customer purchase no profit formation, which is the core of Western $4 \mathrm{C}$ theory. At the same time, we also recognize that, with the consumption level, consumer attitudes change, consumers demand for low-end products gradually reduced, low-end consumer marketing tools and techniques are lost interest, even aversion 
of the emotions. In the face of China's market, it is an extremely urgent market competition situation. Only by constantly digging consumer demand, improving product quality, enhancing product differentiation characteristics, and adapting to the changing media environment, we will upgrade and innovate marketing means. The ultimate change in consumer awareness, in order to maintain market share, otherwise, will be quickly eliminated by the market.

\section{The changes in consumer groups at this stage}

With the development of society and time, in the Chinese market, the core consumer groups mainly by the last century 60's, 70's and 80 's born people, which is what we usually call "60" "After 70", "80 after". As different people have different growth environment and experience background, resulting in their psychological characteristics, consumer attitudes, and behavioural patterns, and many other, have shown great differences.

The face of four different times user groups, and today's society, each person's pursuit of individuality, resulting in a huge difference in consumer behaviour, therefore, for business owners, consumers must be based on the specific circumstances to change the original There are characteristics of the product, change the traditional marketing model, as well as immutable marketing concept to meet different consumer demand. At the same time, business owners also need to have a certain sense of forward-looking, in the face of changes in the mainstream consumer groups, ahead of the layout to meet the arrival of a new era to maintain the capacity of sustainable development.

Competition in the market, the more low-end products are always more intense competition, this is because the low-end goods to meet the needs of consumers at lower levels, consumers do not feel at other levels of "satisfaction", willing to pay the price also will Lower, therefore, the price war will become the only means of competition. Now, with the level of changes in consumer demand, making its demand for high-end will be strengthened, the demand for low-end will be weak, so that product awareness, brand awareness will be in the role of decision-making will be more The greater the impact of price factors on decision-making will be weakened. Faced with this phenomenon, for the market, it should also adjust the positioning of the product under the premise, then adjust its marketing model, which continue to meet the needs of consumers a higher level, making it their most loyal brand Surrounded.

\section{The great changes of the media environment at this stage}

Traditional media presents a digital trend, such as newspapers, magazines, radio, television, etc. With the help of digital technology and network technology to set a variety of media in a "full media" direction, electronic news, e-magazine, mobile news, news sites, Internet radio, network television, digital broadcasting 
Television, mobile TV, etc. have been integrated into the daily lives of ordinary people. The subjects, objects and ways of communication are more complex. The main body of communication spreads from the elite to the common people. The sex, race, age and educational level of the object of communication directly affect the communication effect. The mode of transmission evolves from one-way communication to two-way communication. It can be said that changes in the consumer environment promote the media will change with the media environment changes are also rapid changes in the consumers. Both of which are in the business owners of the marketing strategy have a tremendous impact. Before the emergence of Internet technology and Web2.0 technology, consumers are exposed to the media are one-way communication, the audience can only passively receive the information conveyed by the media, while the media are relatively independent of each other between individuals, the correlation between the lower, the role of each other is also smaller.

In recent years, with the development of technology, the media industry has been the survival of the mass communication model has been gradually subverted, the transmission of the traditional one to many to many to many, the link does not end in the dissemination of Consumers receive the information, and further development, consumers have become part of the follow-up communication links, what is more, consumers are in turn changing the content of mass communication and communication forms. It is precisely in response to today's great changes in consumer behaviour, the vast majority of the media have begun to try and gradually achieve the interactive part of the audience, which also includes the traditional strong media television media, broadcast media, and in-depth coverage Known for print media, and even static display-based outdoor media, are beginning to become interactive. These changes in all aspects of digital, interactive trend, led by the media environment today will be brought into a new but full of new variables. For the enterprise advertisers, the need to understand the background of the times, the characteristics of consumers under the premise of the entire media environment also have a deeper level of grasp in order to better match with the choice of marketing model, so as to achieve the use of media impact of the core Consumer groups, and to achieve its ultimate goal of consumption.

Overall, the current media environment mainly includes the following characteristics:

1. The media platform is not only a platform for receiving information, but also a platform for people to communicate with each other. The media audience has also become a source of information for re-dissemination. The power of information dissemination has exploded. 2. The strengthening of various types of media interactive features, the role of the media audience on the dissemination of content to further deepen, the media operators from the past only ratings, listening, reading and other data is the first look, and now to be able to mobilize the audience participation Interaction as the goal, which can form a social topic, to guide public opinion, to further expand the influence of communication content. 3. By the new generation of consumers to accelerate the pace of life, and lifestyle changes completely changed, the characteristics of the mass media 
becomes more and more obvious in the past, large and medium media structure and dissemination of content has changed, "precision", " Unique positioning "," specialization "," specialization "gradually recognized by the media operators, to find their own unique position in the market and firmly occupy the market, has become a new business philosophy, There have been more and more forms of media, in their respective areas of expertise, vertical and in-depth development. 4. Various types of media have shown strong mobility characteristics, and trying to change through a new era, the first to seize the attention of the core consumer, so in the new media structure, the stage victory. 5. The rapid development of ecommerce, making the media changes directly to the traditional business model had an impact, and the power of this influence is huge, the change is rapid.

\section{The change of enterprise marketing model}

\subsection{The activities marketing: to the direction of social media marketing}

Event marketing has also been translated as event marketing, mainly refers to the enterprise through the intervention or planning a series or a series of large-scale activities and rapidly improved the enterprise and its brand awareness, reputation and influence, promote product sales of marketing. With the rapid development of the Internet, event marketing not only refers to the line under the plane marketing, more online and offline activities that is interactive marketing, and even pure social media marketing model. Since the media era, social media is more close to people's lives, people will usually acquaintances, strangers, workplace (friends circle) and other relationships continue to break down the network and cut to such as micro-blogging, micro letter, easy to believe, Micropoly different social applications such as software. This kind of relationship network with social stickiness holds great brand communication value. The existence of social media for the corporate brand of viral transmission and dissemination of information to provide support for the convenience of the use of social software for consumers to lay the foundation for real-time participation, activities and marketing concept showing a clear socialization, new media Individuality and interactivity of the times are unmistakable.

\subsection{The content marketing: to the panoramic marketing direction}

According to the Content Marketing Association, 93\% of organizations in 2014 said they rely on content marketing to shape their brand and tap demand, with $87 \%$ of consumers claiming that online content has a strong influence on their buying decisions. There is no doubt that content marketing is on the rise. In the past decade, we habitually think that content marketing is the copy, is to write a series of soft paper, the self-proclaimed form of spread of the text to the consumer. In fact, today's content marketing concept is completely different from the past, it can be combined with text, pictures, video, sound and even smell a variety of media, including the use of blog, paste it, instant messaging software 
and other communication channels to disseminate brand content Information, which is distributed throughout the process of communication with consumers, in other words, modern marketing has changed from a simple commodity exchange, evolved into a connected type and continuous interaction, service relationship.

\subsection{Data marketing: of the direction of digital wisdom}

The Internet provides people with convenient online services such as shopping, social networking, and learning while quietly recording data about everyone, such as how long social software is used and how often it is used, personality tags and hobbies, and even life trajectories and property wait. The concept of data marketing is generated in such a digital environment, the data will be more clearly show the characteristics of consumer behaviour in the Internet environment, advertising design and planning can provide scientific basis for precision marketing and improve the user experience to provide data support, but also for the customer group classification, screening to provide a rational clue. Moreover, the effective identification of network data, you can monitor the status of competitors and brand crisis, to provide ideas for public relations decisionmaking. Of course, the network data in the service business marketing, but also for consumers to provide a rational shopping guide.

\section{Conclusion}

In the background of new media, the innovation of marketing strategy is of great practical significance to the management and development of enterprises. It not only helps the enterprises fully realize their own problems in the marketing strategy, but also can formulate the marketing strategy innovative programs meets with the actual situation, greatly enhance the core competitiveness of enterprises, so that enterprises can get long-term healthy development.

\section{References}

[1] Gao Jianzhong. Channel Marketing Management under the Condition of Diversified Market. Finance and Economics, 55(12), pp.68-70, 2011

[2] GUO Jianqing. Research on the level of marketing. Business Culture, 8 (5), pp.87- 91, 2013

[3] Yang Yafei. On the Innovation of Enterprise Marketing Idea under the Condition of Knowledge Economy. Social Science Forum, 12(10), pp. 18- 20, 2012

[4] Zong Zhanguo. Marketing Idea and Marketing Mode Innovation. Business Economics Research, 9(6), pp.58- 61, 2011

[5] Yuan Fei .Analysis of Enterprise Marketing Strategy under New Situation. Enterprise Technology Development, 8(4), pp.85-87, 2014 